\title{
An Empirical Investigation on the Relationship between Carbon Emission and Regional Economic Growth
}

\author{
Song Zhi-Hong, Mao Heng-Chuang, and Lee Dong-Mei
}

\section{ABSTRACT}

\begin{abstract}
The paper empirically investigated the relationship between GDP and carbon emissions in Shanxi Province, P. R. China, from 1998 to 2012. Firstly, the unit root test and co-integration test are carried out for the two time series, and the co-integration equations are obtained. Then the Granger causality test was carried out, and it is found that when the lag order is 3 , the carbon emissions of Shanxi Province is the Granger cause of GDP, while GDP is not the Granger cause of carbon emissions. The conclusion of the study shows that energy consumption in Shanxi Province still brings obvious economic benefits. The economic development of Shanxi Province has not caused a significant increase in carbon emissions in the past 15 years, which may be due to the preliminary effect of the economic transformation of Shanxi Province in recent years. This is consistent with the result that the carbon emission per unit GDP of Shanxi Province shows a downward trend in the past 15 years. Finally, it is put forward that active adjustment of energy structure, development of renewable energy, implementation of technological innovation, optimization of industrial structure and reasonable government intervention are effective measures for sustainable regional economic growth.
\end{abstract}

Keywords: Carbon emission, Granger causality test, Regional economic growth, Unit root test.

\section{INTRODUCTION}

With the rapid development of human economic activities, environmental problems caused by the heavy environmental burden were once almost out of control. Low-carbon Society initiative is one of the various mechanisms that have been deployed to achieve green economic growth, societal wellbeing and development, environmental preservation, and management in a holistic manner [1]. Over the past decade, the theme of environmental protection has been the focus of the world's attention. Environmental problems such as global warming caused by carbon dioxide emissions from economic development are particularly significant. China has taken measures to address climate change, including the establishment of a national carbon trading market, emphasizing the responsibility of provincial governments to meet emissions reduction targets. The environmental negative effects that gradually attach importance to economic development will be gradually attached to economic development, and countries have begun to take measures to avoid environmental deterioration. While much attention has been addressed to China's national level GHG emission, less is known about its regional and sectoral emission features [2].

Most of the existing literature on the relationship between economic growth and carbon emissions is to examine whether they are in line with the Environmental Kuznets curve (EKC) hypothesis. This hypothesis interprets the relationship between carbon emissions and economic growth
Submitted : June 13, 2021

Published : July 05, 2021

ISSN: 2507-1076

DOI: $10.24018 /$ ejbmr.2021.6.4.926

\section{Song Zhi-Hong*}

Institute of Management and Decision, Shanxi University, Taiyuan, P. R. China.

(e-mail: songzhihong ${ }^{\circledR}$ sxu.edu.cn)

Mao Heng-Chuang

School of Economics and Management, Shanxi University, Taiyuan, P. R. China. (e-mail: mhc8545186@qq.com)

Lee Dong-Mei

School of Economics and Management, Shanxi University, Taiyuan, P. R. China.

(e-mail: lidm@sxu.edu.cn)

*Corresponding Author as carbon emissions increase with economic development in the early stage, and gradually decrease with economic growth after reaching a certain point. However, $\mathrm{Wu}$ and $\mathrm{Gu}$ [3] have shown that it is inappropriate to examine the relationship between the two variables with the EKC hypothesis. They have thought that it is more reasonable to study the relationship between the two variables based on causal analysis. In addition, researchers based on the EKC hypothesis often subjectively assume that there is only a onesided causal relationship between potential economic growth and carbon emissions. Carbon emissions per unit of GDP (also called carbon emission intensity, CEI) can be utilized to measure regional carbon emission performance [4].

In fact, we cannot refuse the causal relationship between potential carbon emissions and economic growth [5]. China emits a large amount of anthropogenic carbon, but its carbon emission estimates are highly uncertain [6]. This will make the research results unable to effectively provide guidance for the formulation of economic policies according to the actual situation of energy choice and environment. Emissionsmitigation indicators, such as energy-efficiency targets, should be set relative to physical output (such as tons of steel production) rather than to economic growth [7].

City-level CO2 emission scenarios are important for cities' policies of emission reduction [8]. The relationship between carbon emissions and economic growth described in EKC hypothesis show limitations in China. Carbon emission imbalances of most Chinese regions have been reduced since 
2007[9]. Economic growth and carbon emissions in different regions must be studied as specific situations in different regions. Fuel switching and renewable energy penetration also exhibit positive effect to the $\mathrm{CO} 2$ decrease [10].

\section{DATA SOURCES}

The paper uses the data of energy consumption of Shanxi Province and the carbon emission coefficients provided by the "IPCC National Greenhouse Gas Emission List Guide". The relationship between Carbon dioxide emissions and carbon emissions is a coefficient (44/12), which is the molecular weight ratio of carbon dioxide and the atomic quantity ratio of carbon. Since the linear transformation has no effect on the overall trend of the time series, this paper directly uses carbon emission data to study its relationship with GDP.

Since each category of energy is different, in order to facilitate comparison and further calculation of carbon emissions, the energy consumption data is first converted into the same unit-10,000 tons of standard coal. China defines energy per kilogram of energy for a certain fixed value as a standard coal. All kinds of energy sources are calculated as the same standard coal according to their ability to produce heat from combustion. The specific process is to first calculate the converted standard coal coefficient according to the real combustion heat production capacity of each energy source: Standard coal coefficient equals to the actual heat production per kilogram of a certain energy combustion divided by7000. The data of major energy consumption in Shanxi Province from 1998 to 2012 are converted into unified units.

After obtaining the energy consumption data of unified units, the carbon emissions are weighted according to the 2006 IPCC "National Greenhouse Gas Emission List Guide". In order to exclude the impact of price changes, we consider converting the nominal GDP of Shanxi Province from 1998 to 2012 into constant GDP in 1978.

\section{EMPIRICAL ANALYSES}

\section{A. Unit Root Test}

The unit root test (the ADF test of the extended DickeyFuller) is used to test the stationarity of GDP and CE respectively, and the lag term is determined according to the AIC and SC criteria. The results are shown in Table I.

TABLE I: UNIT ROOT TEST WITH ADF

\begin{tabular}{ccc}
\hline \hline Sequence test forms & The ADF values & The critical values \\
\hline CE $(\mathrm{C}, \mathrm{T}, 0)$ & -1.79135 & $-3.420030(10 \%)$ \\
$\mathrm{GDP}(\mathrm{C}, \mathrm{T}, 0)$ & -1.53463 & $-2.728985(10 \%)$ \\
$\mathrm{CE}(\mathrm{C}, \mathrm{T}, 1)$ & -3.80934 & $-3.388330(10 \%)$ \\
$\mathrm{GDP}(\mathrm{C}, \mathrm{T}, 1)$ & -7.02733 & $-4.992279(1 \%)$ \\
\hline \hline
\end{tabular}

As can be seen from Table I, neither GDP nor CE passed the stationarity test, so the first-order difference was used for the two time series. After the GDP time series are differentiated, the ADF statistical value of the GDP series ($7.02733)$ is less than the critical value $(-4.992279)$ at the $1 \%$ significance level. The results show that there is no unit root for first-order GDP difference. There is no unit root in CE at
$10 \%$ significance level, and it is also a first-order integral time series.

\section{B. Co-integration Test}

From the above analysis, it is shown that the GDP series and the CE series are single integers of the same order. Next, the EG two-step method is selected to test the unit root of the residual error. The results are shown in Table II.

The authors of the accepted manuscripts will be given a copyright form and the form should accompany your final submission.

TABLE II: ADF TEST TABLE OF RESIDUAL ERROR

\begin{tabular}{ccc}
\hline \hline Test form & The ADF value & the critical value \\
\hline $\mathrm{CE}(\mathrm{C}, \mathrm{T}, \mathrm{K})$ & -2.55311 & $-3.420030(10 \%)$ \\
\hline \hline
\end{tabular}

According to Table II, the sequence of residual error is stationary at $95 \%$ confidence level, so CE and GDP are cointegration with the same order. Thus, there is a long-term equilibrium relationship between CE and GDP. The standard co-integration equations of the two variables are obtained by using EVIEWS8.0:

\section{$\mathrm{GDP}=0.038658 \mathrm{CE}$.}

The equation shows that there is a stable relationship between CE and GDP. The economic development of Shanxi Province increases with the increase of carbon emissions, which is consistent with the actual situation that Shanxi Province takes the energy-dependent secondary industry as the main driving force of economic growth.

By calculating the carbon emission intensity per unit GDP, it can be known that the overall carbon emission per unit GDP shows a downward trend during the fifteen years from 1998 to 2012. The growth rate of carbon emissions in Shanxi Province is much lower than that of GDP, which may be related to a series of energy saving and emission reduction policies launched by attaching importance to the environment in recent years and the preliminary results of economic transformation in Shanxi Province.

\section{Granger Causality Test}

The purpose of Granger causality test for the two variables is to investigate whether the two variables have Granger causality or not. It can be seen that when the lag order is 3 , the null hypothesis that CE is not the Granger cause of GDP is rejected at the significance level of 0.01 . CE is considered to be the Granger cause of GDP while GDP is not the Granger cause of CE. This is consistent with the fact that the economy of Shanxi Province is highly dependent on the energy industry.

In recent years, Shanxi Province has advocated emission reduction, environmental protection, and low-carbon economy. In the process of industrial transformation, the economic center of gravity has shifted from the secondary industry to the tertiary industry, promoting the development of the service industry and curbing the energy consumption and carbon emissions of the energy-dependent manufacturing industry, so that the economic growth has not significantly caused the rise of carbon emissions. Table III displays the results of the Granger causality test. 
TABLE III: THE RESULTS OF THE GRANGER CAUSALITY TEST

\begin{tabular}{clccc}
\hline \hline Lag order & \multicolumn{1}{c}{$\mathrm{H}_{0}$} & F-value & P-value & $\begin{array}{c}\text { Accept or refuse the null } \\
\text { hypothesis }\end{array}$ \\
\hline \hline 1 & CE is not the Granger cause of GDP & 2.39101 & 0.1503 & accept \\
& GDP is not the Granger cause of CE & 0.05561 & 0.8179 & accept \\
2 & CE is not the Granger cause of GDP & 1.04317 & 0.3958 & accept \\
& GDP is not the Granger cause of CE & 1.75455 & 0.2335 & accept \\
3 & CE is not the Granger cause of GDP & 17.5462 & 0.0044 & Refuse \\
& GDP is not the Granger cause of CE & 0.28238 & 0.8365 & accept \\
4 & CE is not the Granger cause of GDP & 3.41160 & 0.2393 & accept \\
& GDP is not the Granger cause of CE & 0.24568 & 0.8915 & accept \\
\hline \hline
\end{tabular}

\section{CONCLUSIONS}

\section{A. Conclusions}

Firstly, the co-integration equation obtained above shows that there is a significant linear relationship between carbon emissions and economic growth in Shanxi Province, P.R China. CE and GDP change in the same direction, and this relationship is stable for a long time. This is in line with the fact that Shanxi Province has long formed an industrial structure with energy and raw material industries as its main industries. The uncoordinated industrial structure of Shanxi Province is accompanied by the low scientific and technological content of the energy industry. All these factors contribute to such high carbon emissions in Shanxi Province.

Secondly, from the correlation coefficient of GDP and CE, it can be seen that because carbon emissions mainly come from energy industry, the economy of Shanxi Province is still highly dependent on the secondary industry. This situation is not easy to change in the short-term. The characteristics of energy utilization based on high carbon emissions such as coal also increase the difficulty of emission reduction in Shanxi Province.

Finally, GDP is not CE Granger cause, which to some extent suggests that Shanxi Province should not reduce carbon emissions on the basis of restraining economic development but should seek a sustainable development approach to promote economic growth and reduce environmental pollution, and courage companies to explore new development paths.

\section{B. Policy Implications}

Firstly, it can be seen from previous analysis that the energy consumption of Shanxi Province is mainly coal, and other types of energy are extremely small. The carbon emission coefficient of coal and coke is relatively large. The economy of Shanxi Province is highly dependent on energy and requires a large amount of energy consumption, which is an important reason for the difficulty in controlling and reducing the carbon emission. With the objective of costs minimization, the results indicate that after 2025, the proportion of coal in the country's total energy supply will rapidly decline [11]. Therefore, reasonable adjustment of energy consumption structure is an effective measure to reduce carbon emissions. Secondly, the development of new renewable energy sources, such as solar energy, biomass energy, wind energy, geothermal energy, and so on, can significantly reduce the carbon emission intensity. Considering the long-term interests, the government should strengthen the investments in new energy development and research, support new energy research projects, and guide the change of energy consumption preference, which will prompt the energy structure to gradually change to low emission intensity energy.

Secondly, the promotion of technological innovation will inevitably affect the structure of supply and demand. There is a mismatch between supply and demand in production in Shanxi Province, and the new equipment, new materials and new products required by technological innovation will generate consumer demand, thus adjusting the supply and demand structure and finally changing the economic structure.

Thirdly, the function of technological innovation is to optimize the resource allocation. Carbon capture and storage, a technology that prevents $\mathrm{CO}_{2}$ emitted by coal-burning factories from being delivered into the environment, is one of the best options available with large-scale capacity for China to significantly reduce $\mathrm{CO}_{2}$ emissions from factory sectors in the short run [12].

Fourthly, the economy of Shanxi Province is highly dependent on coal-mining industry, so the focus of the process of industrial structure optimization must be on industry transformation. Under the background of the rising domestic requirements for economic growth quality, it is necessary to upgrade the traditional energy industries in a selective and planned way, making them rationalization and efficient.

\section{REFERENCES}

[1] C. T. Lee, H. Hashim, C. S. Ho, et al. Sustaining the low-carbon emission development in Asia and beyond: Sustainable energy, water, transportation and low-carbon emission technology [J]. Journal of Cleaner Production, Vol. 146, No. 3. pp. 1-13, 2017.

[2] Z. Liu, Y. Geng Y, Lindner S, et al. Uncovering China's greenhouse gas emission from regional and sectoral perspectives [J]. Energy, Vol. 45, No. 1, pp. 1059-1068, 2012.

[3] Q. Wu, S. Gu. Discerning drivers and future reduction paths of energyrelated $\mathrm{CO}_{2}$ emissions in China: combining EKC with three-layer LMDI. [J]. Environmental science and pollution research international, 2021. https://doi.org/10.1007/s11356-021-13129-9.

[4] F. Dong, B. Yu, T. Hadachin, et al. Drivers of carbon emission intensity change in China [J]. Resources, Conservation and Recycling, Vol. 129, pp. $187-201,2018$

[5] P. U. Korkut. Linking renewable energy, globalization, agriculture, $\mathrm{CO}_{2}$ emissions and ecological footprint in BRIC countries: A sustainability perspective [J]. Renewable Energy, Vol. 173, No. 8, pp. 197-208, 2021.

[6] Z. Liu, D. Guan, W. Wei, et al. Reduced carbon emission estimates from fossil fuel combustion and cement production in China [J]. Nature, Vol. 524, pp. 335-338, 2015.

[7] L. Zhu, D. Guan, D. Crawford-Brown, et al. Energy policy: A lowcarbon road map for China [J]. Nature, 2013, 500(7461):143-145.

[8] C. Cui, Z. Wang, B. Cai, et al. Evolution-based $\mathrm{CO}_{2}$ emission baseline scenarios of Chinese cities in 2025 [J]. Applied Energy, Vol. 281, No.1 pp.116116, 2021. 
[9] L. Shao, Y. Li, K. Feng, et al. Carbon emission imbalances and the structural paths of Chinese regions [J]. Applied Energy, Vol. 215, No. 4, pp. 396-404, 2018.

[10] C. Wang, J. Chen, J. Zou. Decomposition of energy-related $\mathrm{CO}_{2}$ emission in China: 1957-2000 [J]. Energy, Vol. 30, No.1, pp. 73-83, 2005.

[11] Z. Wang, Y. Zhu, Y. Zhu, et al. Energy structure change and carbon emission trends in China [J]. Energy, Vol. 115, pp. 369-377, 2016

[12] C. Xu, J. Yang, L. He, et al. Carbon capture and storage as a strategic reserve against China's $\mathrm{CO}_{2}$ emissions [J]. Environmental Development, 2020 (preprint).

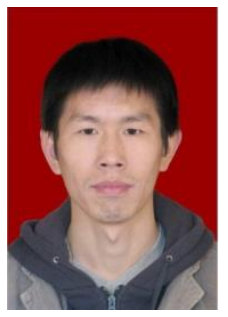

Song Zhi-Hong is a professor in the department of Economics, Institute of Management and Decision, Shanxi University, P. R. China. He received his Master's degree and $\mathrm{Ph}$. D from University of International Business and Economics, P. R. China. His current research interests focus on innovation management, standardization, and sustainable development.

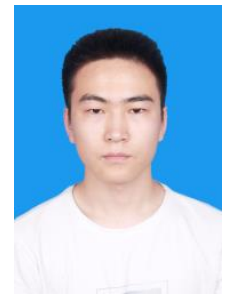

Mao Heng-Chuang is a postgraduate student in School of Economics and Management, Shanxi University, P. R. China. He received his B. A degree from Shanxi University, P. R. China. His current research interests focus on innovation management and standardization.

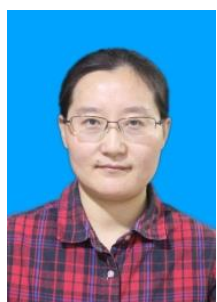

Lee Dong-Mei is an associate professor in the department of Accounting, School of Economics and Management, Shanxi University, P. R. China. She received his Master's degree from School of Mathematics, Shanxi University, P. R. China, and $\mathrm{Ph}$ $\mathrm{D}$ in management from School of Economics and Management, Shanxi University, P. R. China. Her area of specialization is times series analysis, technology management and standard battles. 